\title{
Reversões Repetidas de Discriminações Simples Combinadas com Estímulos Olfativos em Cães Domésticos*
}

\author{
Liane Jorge de Souza Dahás* \\ Universidade de São Paulo, São Paulo, SP, Brasil \\ Izabel Cristina da Silva Brasiliense \\ Carlos Barbosa Alves de Souza* \\ Universidade Federal do Pará, Belém, PA, Brasil
}

\begin{abstract}
RESUMO
Este estudo objetivou ensinar um responder adequado a formação de classes funcionais de estímulos olfativos a três cães domésticos utilizando três fases de treino de reversões repetidas e combinadas de discriminações simples combinadas: (1) com dois estímulos; (2) em pares com dois conjuntos de estímulos e (3) com quatro estímulos. Os sujeitos aprenderam as tarefas nas Fases 1 e 2. Um dos sujeitos apresentou learning set da tarefa na Fase 1, mas nenhum apresentou responder condizente com a formação de classes. Discute-se que a exigência de discriminar quatro estímulos na mesma tentativa tornou a tarefa complexa demais para os cães e sugere-se um novo estudo para tratar com essa dificuldade.
\end{abstract}

Palavras-chave: reversões repetidas de discriminações simples combinadas; classes funcionais; cães domésticos.

\begin{abstract}
Repeated Yoked Reversals of Simple Discriminations with Olfactory Stimuli in Domestic Dogs

This study aimed to install an adequate response to the formation of functional classes of olfactory stimuli in three domestic dogs through training repeated and yoked reversals of simple discriminations in three phases: (1) with two stimuli (2) in pairs with two sets of stimuli, and (3) with four stimuli. The subjects learned the tasks in Phases 1 and 2, and one of them showed learning set of the task in Phase 1; but none responded in a way befitting the formation of functional classes. It is argued that the requirement to discriminating four stimuli in the same trial made the task too complex for the dogs, and a new study is suggested to deal with this difficulty.
\end{abstract}

Keywords: repeated and yoked reversals of simple discriminations; functional classes; domestic dogs.

A relação entre a formação de classes funcionais de estímulos (Goldiamond, 1966) e a equivalência de estímulos (Sidman \& Tailby, 1982) vêm sendo discutidas no âmbito da Análise Experimental do Comportamento desde o artigo pioneiro de Vaughan (1988). Tem sido investigado o papel que esses fenômenos podem ter no estudo dos repertórios simbólicos e pré-simbólicos (Dahás, Brasiliense, Costa, Barros, \& Souza, 2010; Kastak, Schusterman, \& Kastak, 2001; Sidman, Wynne, Maguire, \& Barnes, 1989).
Para Vaughan (1988), a equivalência de estímulos pode ser caracterizada em termos do resultado de uma história de reforçamento para responder diferencialmente a conjuntos de estímulos, de maneira que os estímulos de um conjunto formam uma classe funcional. Dessa forma, um treino de reversões repetidas de discriminações simples combinadas (RRDSC) pode gerar um responder semelhante ao encontrado quando se realiza treinos com o procedimento de pareamento ao modelo, comumente utilizado em pesquisas visan-

* Endereço para correspondência: Liane Dahás - lianedahas@gmail.com

* Endereço para correspondência: Carlos Barbosa Alves de Souza - carlos.souza@pesquisador.cnpq.br 
do à emergência de relações de equivalência (e.g., Sidman \& Tailby, 1982 - para uma discussão mais detalhada desse argumento e de suas críticas, ver Dahás et al., 2010).

Vaughan (1988) treinou seis pombos (Columba livia) a responder em diferencialmente a dois grupos de 20 figuras de árvores cada um, por meio de um procedimento de RRDSC. A tarefa consistia no bicar do pombo a uma chave central abaixo da tela de computador quando apresentado o estímulo correto e no não bicar quando apresentado o estímulo incorreto. Para que ocorresse a reversão foi utilizado um critério arbitrário e variável por número de sessões realizadas. Verificou-se que, ao longo de uma série de reversões, o responder dos pombos adaptava-se às mudanças de contingência cada vez mais rapidamente, com erros somente nas primeiras tentativas, para os dois grupos de estímulos. Desta forma, foi possível constatar que os dois grupos se tornaram duas classes de estímulos discrimináveis e funcionalmente diferentes, indicando formação de classes funcionais.

Lionello-DeNolf, McIlvane, Canovas, de Souza e Barros (2008) discutiram a formação de classes funcionais em crianças com desenvolvimento típico e em crianças diagnosticadas com autismo em termos de learning set da tarefa de RRDSC. Learning set pode ser definido enquanto "um melhoramento progressivo na taxa de aprendizagem de uma série de problemas de discriminação, cada qual tendo a mesma solução geral" (Slotnick, Hanford, \& Hodos, 2000, p. 411; ver também, Harlow, 1949, para o primeiro uso do termo) ${ }^{1}$. Para Lionello-DeNolf et al., o aprendizado da tarefa de responder adequadamente a reversão recorrente de função dos estímulos (ou seja, o responder eficiente às contingências de reversão) pode promover ou facilitar a formação das classes de estímulos que compartilham a mesma função no treino. Nesse sentido, o learning set de reversão e a formação de classes funcionais funcionariam como dois pontos de um continuum lógico de aprendizagem.

Domeniconi, Bortoloti, Antoniazzi e Mendes (2008) apresentaram com cães domésticos (Canis familiares) um dos poucos resultados positivos de formação de classes funcionais de estímulos por meio de um treino de RRDSC. A partir da confirmação das habilidades comunicativas dessa espécie na sua relação com a espécie humana (Kaminski, Call, \& Fisher, 2004; Soproni, Miklósi, Csányi, \& Topál, 2001;
Wobber, 2005), vem crescendo o número de estudos que buscam esclarecer o potencial do cão doméstico como um modelo animal de aspectos da cognição humana (ver Range, Aust, Steurer, \& Huber, 2008; Udell \& Wynne, 2008).

Domeniconi et al. (2008) treinaram três cães em um procedimento de RRDSC com estímulos visuais. Três pares de estímulos visuais (utensílios domésticos ou brinquedos) foram treinados separadamente (A1A2, B1B2 e C1C2). A tarefa consistia na apresentação simultânea de dois estímulos e o cão deveria responder saltando por uma placa de madeira em direção a um destes. A consequência para escolha correta consistia no acesso ao item alimentício específico da classe (R1 para a classe 1 quando positiva e R2 para a classe 2 quando positiva).

Os testes consistiram de reversões das funções dos estímulos, que eram todos apresentados, cada par por tentativa, em uma mesma sessão. Foram realizadas seis sessões de teste com dois sujeitos e sete com o terceiro. Somente uma sessão de um sujeito e duas de outro apresentam escores abaixo de $90 \%$ (85\% para um sujeito e $67 \%$ e $84 \%$ para outro). O responder adequado nas primeiras tentativas em que cada par de estímulos foi apresentado também teve alta ocorrência: dois sujeitos apresentaram somente um erro, e outro, dois erros. Essa análise é importante, já que os testes eram realizados com consequência para o responder correto. Tais resultados apontaram para a formação de classes. Domeniconi et al. (2008) indicaram ainda que as poucas sessões (de 33 a 39) necessárias para o alcance de critério durante o treino era um bom indicativo de que a espécie canina se adapta bem ao procedimento utilizado.

Dahás et al. (2010) replicaram com dois cães o estudo de Barros, Souza e Costa (2013) sobre a formação de classes funcionais com macacos-prego (Sapajus sp.) em uma tarefa de forrageio. Barros et al. treinaram dois macacos-prego a forragear em duas, quatro, e posteriormente, seis caixas, divididas igualmente em duas classes. O procedimento de treino de reversões repetidas de discriminações simples combinadas consistia em apresentar inicialmente, somente duas caixas ao sujeito (uma com função positiva e outra negativa) e, posteriormente, quatro e seis caixas.

O responder dos sujeitos de Barros et al. (2013) foi similar aos descritos para os sujeitos de Vaughan (1988), no sentido em que as respostas erradas ocorriam 
somente no início da sessão, adequando-se à contingência de reversão em vigor, de maneira que, mesmo após ter sido exposto somente a determinado estímulo de uma classe, os sujeitos já passavam a responder aos outros estímulos da mesma classe de maneira semelhante (funcionalmente equivalentes). Barros et al. realizaram, como teste, a retirada de dois estímulos (cada um de uma classe), reversão da função dos quatro estímulos restantes e posterior inserção dos estímulos retirados anteriormente. Dessa forma, foi possível averiguar como se dava o responder dos sujeitos frente a esses estímulos com a função alterada com relação à que tinham quando de sua última apresentação.

Ambos os sujeitos responderam aos estímulos reinseridos de acordo com as contingências que vigoravam nessa mesma sessão para os outros estímulos já apresentados. Ou seja, mesmo que a função de um determinado estímulo tivesse sido positiva no último contato que os sujeitos tiveram com ele antes do teste (escolhê-lo levava à liberação de reforço), na sessão de teste os sujeitos não escolhiam tal estímulo, já que os outros estímulos da mesma classe apresentavam função negativa no início dessa sessão.

Em busca de replicação de tais dados com a espécie canina, Dahás et al. (2010) expuseram dois cães domésticos a um treino de RRDSC com seis estímulos visuais apresentados simultaneamente na mesma tentativa. Serviam como estímulos caixas de madeira que permaneciam na mesma posição no decorrer do experimento e eram caracterizadas por figuras geométricas colocadas na frente das caixas, por um brinquedo inflável anexado a cada caixa e por uma cor. O responder correto em uma tentativa era entrar nas caixas com função positiva, uma por uma, independente da ordem das respostas, e retornar ao experimentador sem entrar em nenhuma caixa com função negativa. Primeiro foi realizado um treino com duas caixas, depois com quatro e, por fim, com as seis caixas. Os testes consistiram na retirada de duas caixas, reversão de função dos estímulos e reinserção dessas caixas. Esperava-se que os sujeitos, ao responderem adequadamente à reversão de função de parte dos estímulos da classe, o fariam também para os estímulos reinseridos.

Os treinos resultaram em um responder muito semelhante aos dos sujeitos do estudo de Vaughan (1988), visto que os dois sujeitos passaram a acertar as tentativas pós-reversão de função logo no início das sessões. Já os resultados dos testes não foram conclusivos, mas houve indícios de que a localização fixa das caixas no decorrer do estudo tenha controlado mais o responder dos sujeitos do que as características visuais das mesmas.

Durante a evolução, a visão canina foi adaptada para locais com pouca iluminação, de maneira que a visão de cores não é idêntica à de humanos (cães são dicromatas, enquanto os humanos são tricromatas), e a acuidade visual é cerca de três vezes pior que a humana (Miklósi, 2007). Já a olfação em cães é reconhecidamente muito superior do que a humana, tendo os cães cerca de 220 milhões a 2 bilhões de neurônios olfativos, enquanto humanos tem entre 12 e $40 \mathrm{mi}$ lhões (Miklósi, 2007). Dessa forma, acredita-se que o estudo sobre a formação de classes funcionais de estímulos possa se beneficiar de um procedimento que utilize estímulos olfativos tendo-se cães como sujeitos.

Williams e Johnston (2002) realizaram um procedimento de formação de duas classes de 10 estímulos olfativos cada (não foram realizados treinos de reversão de função de estímulos). Os sujeitos foram quatro cães mestiços, e o aparato experimental consistia em 20 latas que ficavam em uma extremidade de uma prancha de madeira. Na outra extremidade era anexado um encaixe que funcionava para o experimentador segurar as pranchas para movê-las de lugar sem tocar as latas, evitando o risco de misturar odores. As pranchas eram dispostas de maneira que formassem um círculo (com as latas para o lado de fora do círculo), e eram reposicionadas a cada tentativa.

$\mathrm{O}$ procedimento geral consistia em treinar o cão a cheirar todas as latas, andando de uma para outra. Quando o cão cheirasse uma lata do grupo positivo, a resposta de sentar ao lado da lata era consequenciada com um pedaço de alimento. A resposta de andar para a lata ao lado após cheirar uma lata pertencente ao grupo negativo não era consequenciada e respostas erradas, como sentar após cheirar uma lata do grupo negativo ou andar para a lata ao lado após cheirar uma lata do grupo positivo, eram consequenciadas com a repetição da tentativa (procedimento de correção).

O treino foi feito de maneira que gradualmente novas latas eram adicionadas às sessões, finalizando com sessões nas quais as 20 latas estavam disponíveis para que os sujeitos cheirassem. $\mathrm{O}$ estudo resultou no responder adequado às duas classes de estímulos olfativos por todos os sujeitos. Os autores afirmam que o procedimento se mostrou adequado para o estudo da detecção de substâncias por cães domésticos. 
Nota-se que, além do uso de substâncias com odores em vez de estímulos visuais, comumente usados em estudos de formação de classes, Williams e Johnston (2002) também controlaram uma variável que provavelmente interferiu nos resultados de Dahás et al. (2010): a posição variada das latas não permitia outra forma de controle para o responder dos sujeitos além do requerido pelos experimentadores.

O presente experimento é a primeira tentativa descrita na literatura de realizar um treino de formação de classes funcionais com estímulos olfativos em cães domésticos. Para isso, realizou-se um procedimento de formação de classes funcionais utilizando-se estímulos olfativos (uma modalidade sensorial mais adequada para a espécie canina) e reposicionando-os a cada tentativa, buscando assim confirmar o único dado atual sobre formação de classes funcionais via procedimento de RRDSC em cães domésticos (Domeniconi et al., 2008). Os dados são discutidos em termos de existência ou não de learning set da tarefa de RRDCS, ou seja, verifica-se se os alcances de critério estabelecidos para cada reversão de função passaram a ser alcançados, no decorrer do treino, em um menor número de sessões.

\section{MÉTODO}

Sujeitos: participaram desse estudo os dois sujeitos do experimento de Dahás et al. (2010), Lucke (macho daschund mestiço de três anos) e Yumi (fêmea yorkshire de dois anos), e um sujeito ingênuo experimentalmente, Mila (fêmea yorkshire de um ano e meio). Os sujeitos eram animais domésticos trazidos ao laboratório da UFPA para as coletas de dados. Foi solicitado aos donos dos sujeitos que não os alimentassem após as 23 horas.

Ambiente e Equipamentos: os dados foram coletados em uma sala (5 x 5,5 m), com iluminação artificial e climatizada do Laboratório de Psicologia Experimental da UFPA. O aparato experimental foi baseado no estudo de Williams e Johnston (2002). Foram utilizadas seis pranchas de madeira $(0,6 \times 0,13 \mathrm{~m})$ com uma alça (puxador de gaveta) em uma das extremidades e, na outra extremidade, um recipiente de plástico contendo um pedaço de algodão molhado com uma substância aromática. A alça foi utilizada para movimentar o aparato do lugar durante as sessões, evitando assim que o experimentador tocasse nos recipientes plásticos, misturando odores. Embaixo de cada prancha foi escrito o nome da substância colocada no recipiente. As pranchas encaixavam-se em um tabuleiro de madeira $(92,5 \times 2,00 \mathrm{~m})$, a aproximadamente $18 \mathrm{~cm}$ de distância uma da outra. Havia seis encaixes no tabuleiro, de maneira que seis pranchas podiam ser apresentadas simultaneamente em uma mesma tentativa ao sujeito. As pranchas ficavam entre dois biombos (aproximadamente a 1,5 m de cada), sendo que um deles tinha um espelho unidirecional de $20 \times 30 \mathrm{~cm}$ na parte superior.

Foi utilizado ainda um clicker para produzir um som que funciona comumente como reforçador condicionado no treinamento de cães (Rossi, 2008), folhas de registro para anotar as respostas dos sujeitos, que também continha as posições a serem colocadas as pranchas a cada tentativa, um cronômetro para contabilizar apresentações de time-out (ver Procedimento) e uma câmera de vídeo para registrar algumas sessões de treino e os testes.

Luvas descartáveis eram utilizadas sempre que um recipiente ia ser aberto ou fechado (antes e depois de cada sessão). Para cada substância, um par de luvas (descartado ao final da coleta do dia) era utilizado, o que evitava que os cheiros das substâncias se misturassem. Sempre que as substâncias eram trocadas (o que ocorria uma vez por semana) eram utilizados pedaços de algodão e seringas. Era colocado um pedaço de algodão em cada recipiente, dispensado $2 \mathrm{ml} \mathrm{de}$ cada substância em seu próprio recipiente e depositado outro pedaço de algodão de maneira que nenhuma dica visual pudesse ser dada aos sujeitos ao olhar para dentro do recipiente.

Estímulos Reforçadores: pedaços de alimentos, como bifinhos, snacks, biscoitos para cães e bolachas cream-cracker, além de elogios emitidos pelo experimentador que conduzia o sujeito ("muito bem", "parabéns", "é isso aí, garoto/a", "perfeito, [nome do animal]") eram utilizados como reforçadores. O responder correto de Lucke também era consequenciado pela apresentação de brinquedos variados (um brinquedo de borracha, pelúcia, uma bola, etc.).

Estímulos Discriminativos: foram selecionadas seis substâncias diferentes, sendo colocada uma em cada recipiente. Duas substâncias, 'café' e 'essência perfumada para ambientes', foram utilizadas na modelagem e na Fase 1 (descrita a seguir). As outras quatro substâncias foram escolhidas por terem odores diferentes e serem atóxicas (ver Williams \& Johnston, 
2002). Essas foram divididas de maneira aleatória para comporem duas classes de estímulo: Classe 1 (A1) Ciclohexanona e (B1) Eucaliptol; e Classe 2 (A2) Octanol 2 e (B2) Benzaldeído.

\section{Procedimento}

Eram realizadas de uma a quatro sessões por dia com cada sujeito, cinco vezes por semana (ou menos, dependendo de situações como estado de saúde e condições de transporte). A duração das sessões variava entre 15 e 40 min. aproximadamente, dependendo da fase realizada, do número de sessões e do sujeito. Quando ocorria um alcance de critério, a reversão de função só era apresentada em uma sessão no dia seguinte, nunca no mesmo dia.

No início de cada tentativa, o sujeito era mantido preso à coleira por um experimentador (E1) atrás de um biombo, impedindo a visualização dos recipientes tanto pelo sujeito quanto pelo E1. As pranchas ficavam dispostas no chão da sala, lado a lado, distantes $20 \mathrm{~cm}$ uma da outra. Através do outro biombo, um segundo experimentador (E2) observava as tentativas e indicava, com o acionamento do clicker, para E1 (que conduzia o sujeito) se o responder foi adequado à substância presente no recipiente em questão naquela tentativa ou não (as consequências específicas para cada responder serão descritas a seguir).

O E2 mudava as pranchas de posição a cada tentativa, seguindo uma planilha com as posições a serem dispostos no tabuleiro, enquanto o sujeito estava escondido atrás do biombo. Semanalmente, as substâncias eram repostas nos recipientes por E2.

Uma tentativa consistia no E2 retornando ao biombo, sinalizando verbalmente ao E1 o início da tentativa ("Pode começar"), no posicionamento do sujeito pelo E1 no meio da sala, de frente para o tabuleiro contendo as pranchas, e na liberação da coleira do sujeito pelo E1. Foram modeladas as respostas de focinhar os recipientes, sem ordem pré-estabelecida, e de sentar na frente do que contivesse substância com função de estímulo positiva logo após focinhá-lo. Uma tentativa era definida pela liberação de um sujeito para que focinhasse e sentasse nos recipientes dispostos, e era encerrada (1) após o focinhar e sentar frente a todos os recipientes contendo substâncias com função positiva (considerado um acerto) ou (2) após o focinhar e sentar frente a um recipiente contendo substância com função negativa (considerado um erro).
Em uma sessão com quatro recipientes, por exemplo, dois deles continham substâncias pertencentes à classe de estímulos positivos e os outros dois, de estímulos negativos. $\mathrm{O}$ sujeito ficava livre para cheirar qualquer um dos recipientes e sentar na frente deles. No entanto, somente o focinhar um recipiente seguido do sentar na frente do mesmo recipiente contendo substância com a função positiva (denominado recipiente $\mathrm{S}+$ ) era consequenciado com o som do clicker, a liberação de um pedaço de alimento e um elogio (além do brinquedo, no caso de Lucke). O focinhar um recipiente e não sentar na frente do mesmo recipiente não tinha consequência programada (o sujeito permanecia com a guia da coleira solta para cheirar os outros recipientes).

Uma tentativa só era finalizada e considerada correta se o sujeito respondesse corretamente a todos os recipientes $\mathrm{S}+$, sem a ocorrência de um focinhar seguido de sentar em frente a um recipiente contendo substância com função de estímulo negativa. Logo após o focinhar seguido do sentar em frente ao último recipiente $\mathrm{S}+$, E1 levava o sujeito para o biombo, onde liberava dois pedaços bônus de alimento (e no caso de Lucke, um brinquedo). A entrega desses pedaços bônus de alimento objetivava minimizar os erros. Enquanto isso, E2 anotava a resposta do sujeito e modificava a posição das pranchas. Dessa maneira, não havia um intervalo entre tentativas (IET) exato, dependendo sempre da velocidade com que E2 modificava a posição das pranchas, além do tempo de consumo do bônus pelo sujeito.

Uma tentativa era finalizada e considerada uma tentativa incorreta quando ocorria o focinhar um recipiente contendo substância com função negativa (denominado recipiente $\mathrm{S}$-) e posterior sentar na frente do mesmo recipiente. Mesmo que o sujeito tivesse realizado um focinhar seguido de sentar em frente ao recipiente $\mathrm{S}+$ no início dessa tentativa, o subsequente focinhar e sentar frente a um recipiente $S$ - levava à finalização dessa tentativa, considerada incorreta. Após uma tentativa incorreta, era realizado um timeout de $15 \mathrm{~s}$, que consistia no apagar das luzes pelo E2 e no afastar do sujeito das pranchas pelo E1, puxando a guia da coleira (E1 controlava o tempo de time-out usando cronômetro). Finalizado o time-out, E2 acendia as luzes e a tentativa era repetida (caracterizando uma tentativa de correção). Caso o sujeito sentasse em um recipiente com função de $S$ - na primeira tentativa de correção, outra tentativa de correção era realizada. 
No entanto, se o responder fosse incorreto nessa também, a próxima tentativa de correção (terceira) seria com escolha forçada do S+: E2 dizia para E1 quais os recipientes eram positivos, e E1 indicava quais eram os recipientes contendo os cheiros com função positiva para o sujeito (apontando para eles e falando "cheira", e depois "senta"). A consequência para essa terceira tentativa de correção era um clique a cada responder correto e um pedaço de alimento quando o sujeito retornasse ao biombo.

Somente E2, que movia os aparatos, sabia quais continham substâncias das Classes 1 e 2. Durante o responder do sujeito, E2 ficava atrás do biombo com espelho unidirecional, de maneira a poder ver o desempenho e indicar através do clicker ao E1 quando fornecer alimento ou, através do apagar das luzes, quando liberar um time-out e realizar uma tentativa de correção. Dessa maneira, ficou reduzida a possibilidade do responder correto do sujeito ser controlado por dicas fornecidas pelo experimentador.

Inicialmente foi realizado um procedimento de modelagem das respostas de ir a um recipiente e cheirá-lo e de sentar através do método explicitado no livro 'Treinamento Inteligente' (Rossi, 2008). Depois disso, o treinamento da tarefa de reversões repetidas de discriminações simples combinadas (RRDSC) com estímulos olfativos teve início. O critério para realizar reversões na função dos estímulos em todas as fases foi de seis tentativas corretas consecutivas em uma sessão, desconsiderando tentativas com correção. O treino de RRDSC foi implementado em três fases.

Fase 1 - Treino inicial com dois estímulos olfativos. Esse treino inicial consistiu em um treino de RRDSC com os estímulos 'café' e 'essência'. Foram estabelecidos dois critérios de finalização dessa fase (o que ocorresse primeiro): 39 sessões de 18 tentativas com cada sujeito, ou o alcance de critério de seis tentativas corretas consecutivas em seis sessões consecutivas. O objetivo desse treino foi testar se o equipamento e o próprio procedimento geral eram suficientes para instalar um repertório adequado às reversões de função de discriminação simples.

Fase 2 - Treino de RRDSC com dois recipientes por sessão, até que quatro (A1, B1, A2 e B2) dos seis recipientes tivessem funcionado uma vez como estímulo positivo ( $\mathrm{S}+$ ) e outra como estímulo negativo (S-). O treino ocorreu de maneira que o $\mathrm{S}+$ do par que estava sendo treinado não aparecia como S- após a reversão na função dos estímulos (procurando evitar um efeito de persistência comportamental - ver Rico, 2006). O estímulo anteriormente negativo adquiria a função positiva com a reversão. Quatro subfases foram realizadas, apresentando-se sempre um par de estímulos a ser discriminado: A1+B2- (A1 com função positiva e B2 com função negativa), B2+B1-, B1+A2-, A2+A1-. As sessões tinham 18 tentativas. $O$ objetivo dessa fase consistia em verificar a possibilidade de discriminação entre os estímulos a serem utilizados no treino de formação de classes. $\mathrm{O}$ critério de término da fase era o de ocorrência de seis tentativas corretas consecutivas em cada discriminação.

Fase 3 - Treino de RRDSC com os quatro recipientes da Fase 1 (A1, B1, A2 e B2) apresentados juntos nas tentativas, de maneira a possibilitar a formação das classes funcionais. Inicialmente dois recipientes de uma classe eram designados como estímulos positivos $(\mathrm{S}+[\mathrm{s}])$ e os outros dois da outra classe como estímulos negativos ( $\mathrm{S}-[\mathrm{s}]$ ). Com o alcance do critério de seis tentativas corretas consecutivas, a função dos estímulos era revertida. As sessões tinham 18 tentativas. No decorrer das sessões dessa fase, verificar-se-ia se foram formadas classes funcionais, ou seja, se os sujeitos erravam no máximo a primeira tentativa e já passavam a responder nos estímulos da outra classe após cada reversão de função. Se, em 70 sessões, o responder não se adequasse ao conceito de classes funcionais formulado por Vaughan (1988), o experimento seria encerrado. Tal critério de término buscou expor os sujeitos do presente estudo a um número de sessões superior ao de sessões realizadas pelos sujeitos de Barros et al. (2013) e Domeniconi et al. (2008), que apresentaram responder de acordo com as classes propostas pelos experimentadores. Os dois sujeitos do Experimento 1 de Barros et al. demonstraram learning set da tarefa de RRDSC com 10 e 11 sessões com quatro estímulos por tentativa, e com mais 12 e 11 sessões com seis estímulos. Os sujeitos de Domeniconi et al. realizaram entre 33 e 39 sessões para alcançarem o critério de término dos treinos.

\section{RESULTADOS}

\section{Fase 1 - Treino inicial de RRDSC com 'café' e 'es- sência'}

De maneira geral, os resultados dos sujeitos sugeriram um responder discriminado entre os estímulos 
'café' e 'essência' na Fase 1 (mas ver os resultados de Lucke na Fase 3). A Figura 1 mostra o número de sessões realizadas por Lucke, Yumi e Mila para cada alcance de critério (quantidade de sessões necessárias para obtenção do critério de aprendizagem) nessa fase. Os alcances de critério realizados com a substância 'café' como estímulo positivo, marcados com a letra "c" no eixo x da Figura 1, foram realizados com o seguinte número de sessões: seis alcances em 17 sessões, 10 alcances em 19 sessões e sete alcances em 16 sessões para Lucke, Yumi e Mila, respectivamente. Os alcances de critério realizados com a substância 'essência' como estímulo positivo foram marcados com a letra "e" no eixo x (Figura 1). Lucke, Yumi e Mila realizaram cinco alcances em 22 sessões, nove alcances em 20 sessões e sete alcances em 15 sessões, respectivamente, com essa substância. $\mathrm{O}$ critério para reversão de função foi alcançado por Lucke 12 vezes em um total de 39 sessões, por Yumi 20 vezes em um total de 39 sessões, e por Mila 14 vezes em um total de 31 sessões.

Nota-se que Mila alcançou o critério de seis tentativas corretas consecutivas em seis sessões consecutivas, o que levou ao encerramento da fase antes da realização de 39 sessões. Os dados de Mila demonstram learning set da tarefa de RRDSC entre as reversões 1 e 14.

Os dados da Figura 1 demonstram também o alcance de critério com menos sessões por Yumi, o que pode funcionar como indício de que ela estivesse apresentando learning set da tarefa de RRDSC. Já os dados de Lucke demonstram que ele não aprendeu no decorrer das sessões a realizar tarefas de RRDSC de maneira cada vez mais rápida, ou seja, não há, para esse sujeito, dados que indiquem learning set da tarefa nessa fase.

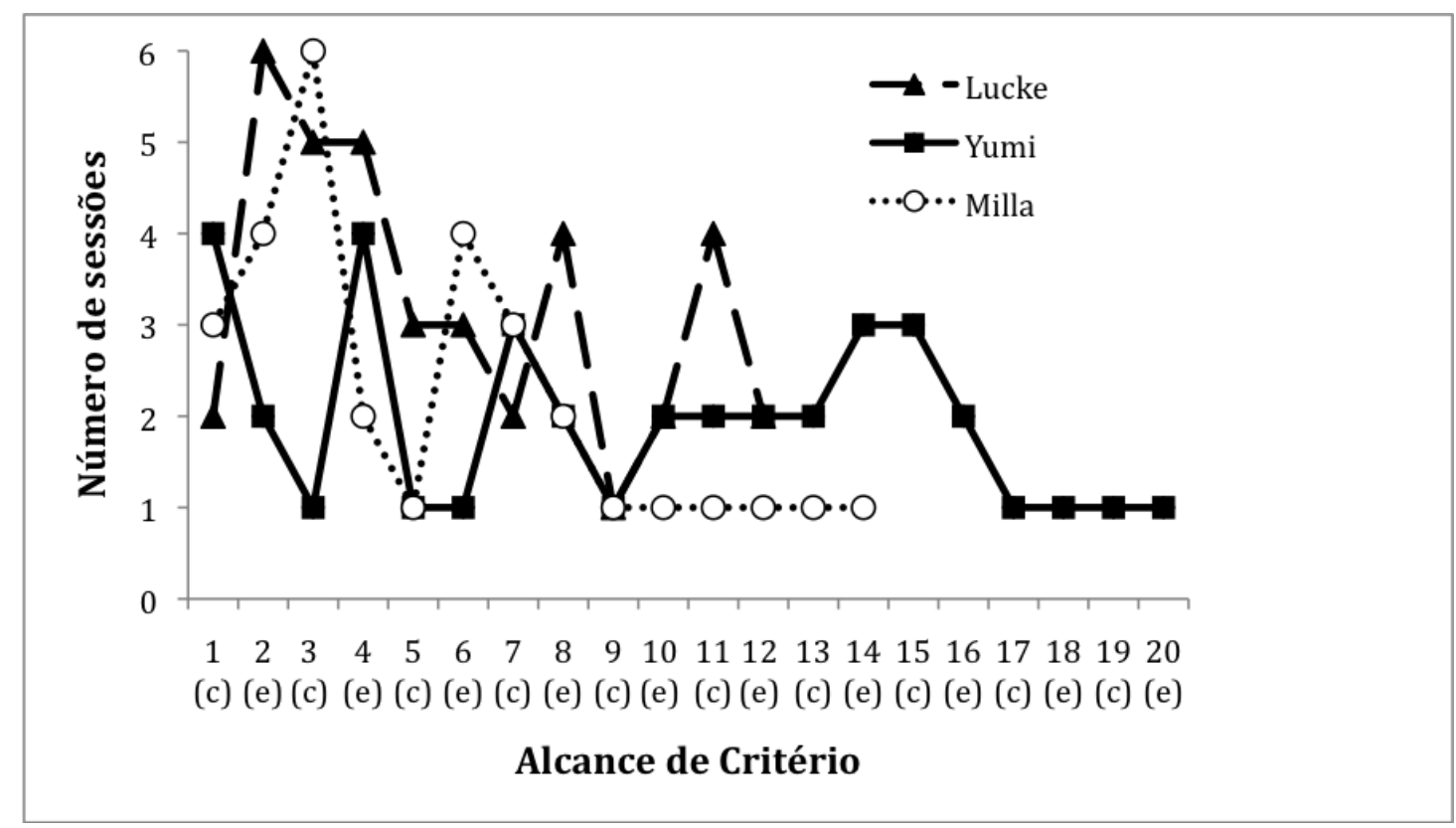

Figura 1. Número total de sessões realizadas até critério para reversão de função com Lucke, Yumi e Mila na Fase 1. Em parênteses no eixo x, estão indicados os estímulos utilizados como S+ ('café' - c / 'essência' - e) em cada alcance.

\section{Fase 2 - Treino de RRDSC com dois recipientes por sessão}

Lucke, Yumi e Mila alcançaram os quatro critérios necessitando de um total de treze, quatro e sete sessões, respectivamente (ver Figura 2). Lucke realizou uma sessão para alcance do critério com a substância
A1 como positiva, três com a substância B2, três com a substância B1 e seis com a substância A2. Yumi realizou uma sessão para alcançar o critério de aprendizagem para cada uma das substâncias. Mila necessitou de duas sessões para A1, B2 e B1, e uma sessão para A2. 


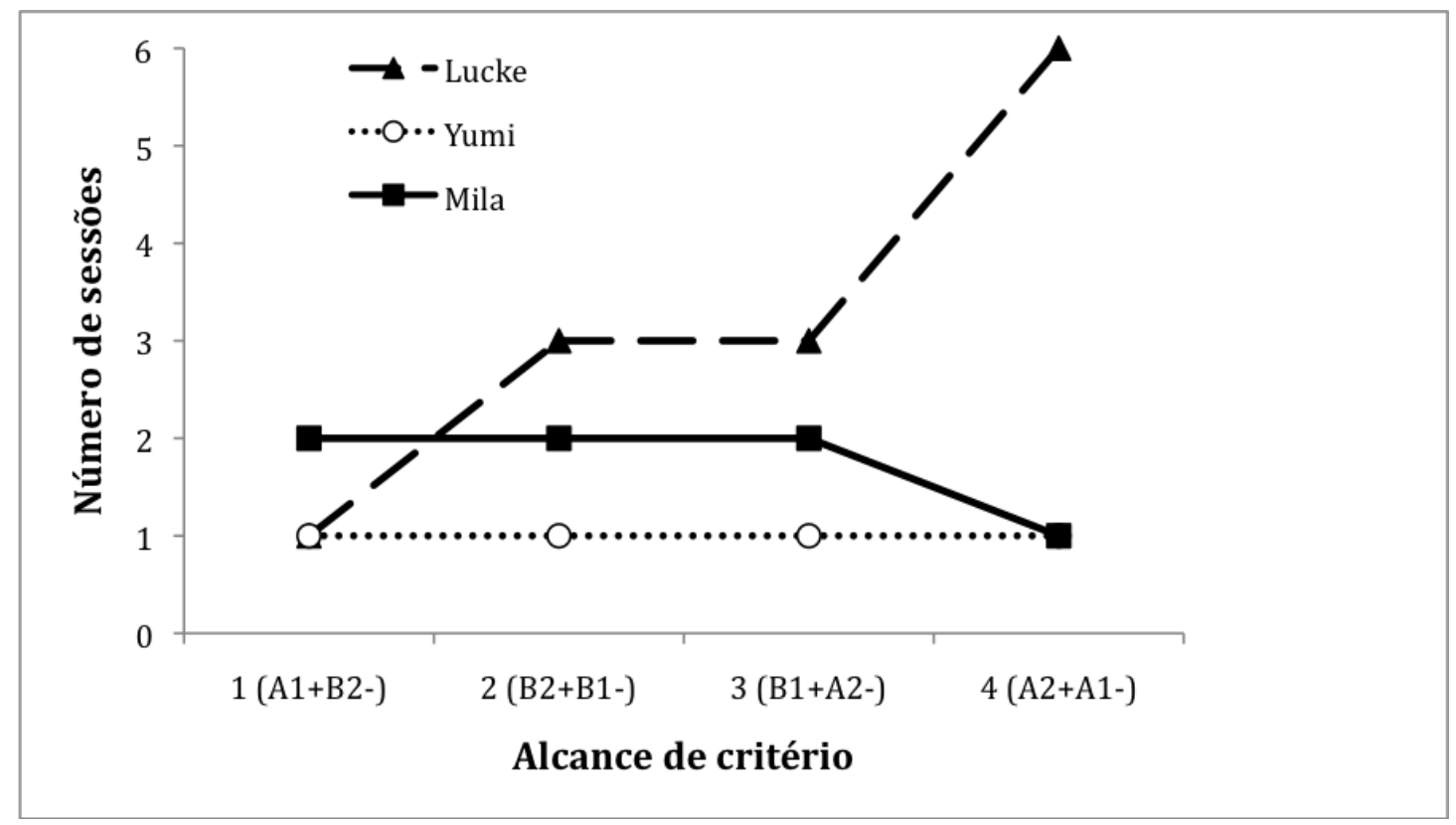

Figura 2. Quantidade de sessões realizadas até critério para reversão de função com Lucke, Yumi e Mila na Fase 2. Em parênteses no eixo x, os estímulos utilizados como S+ e como S- estão explicitados em cada alcance.

\section{Fase 3 - Treino de RRDSC com quatro recipientes por sessão (treino de formação de classes)}

Lucke necessitou de 18 sessões para alcançar pela primeira vez o critério de reversão de função tendo as substâncias A1B1 como estímulos positivos e A2B2 como estímulos negativos. No entanto, verificou-se nessa Fase que o responder do sujeito estava sob controle da posição em que os estímulos positivos se encontravam na tentativa anterior, visto que o sujeito respondia consistentemente quando as substâncias com função negativa se encontravam nas posições onde as com função positiva tinham estado na tentativa anterior. Assim, foi retomada a Fase 1 do treino de RRDSC com o sujeito buscando-se garantir o controle de seu comportamento pelo odor da substância contida no recipiente, e não pela posição (ver descrição dos dados mais adiante).
A Figura 3 mostra o número de sessões realizadas por Yumi e Mila para cada alcance de critério na Fase 3. Os alcances de critério realizados com o par de substâncias A1B1 como positivo estão indicados com o número " 1 " entre parênteses no eixo x (seis alcances em 34 sessões para Yumi e dois alcances em oito sessões para Mila), e os alcances de critério pares com o par de substância A2B2 como positivo estão identificados com o número " 2 " entre parênteses no eixo x (três alcances em 15 sessões para Yumi e dois alcances em oito sessões para Mila).

Yumi alcançou 11 vezes o critério para reversão de função em um total de 64 sessões. Mila alcançou quatro vezes o critério para reversão de função em 16 sessões. 


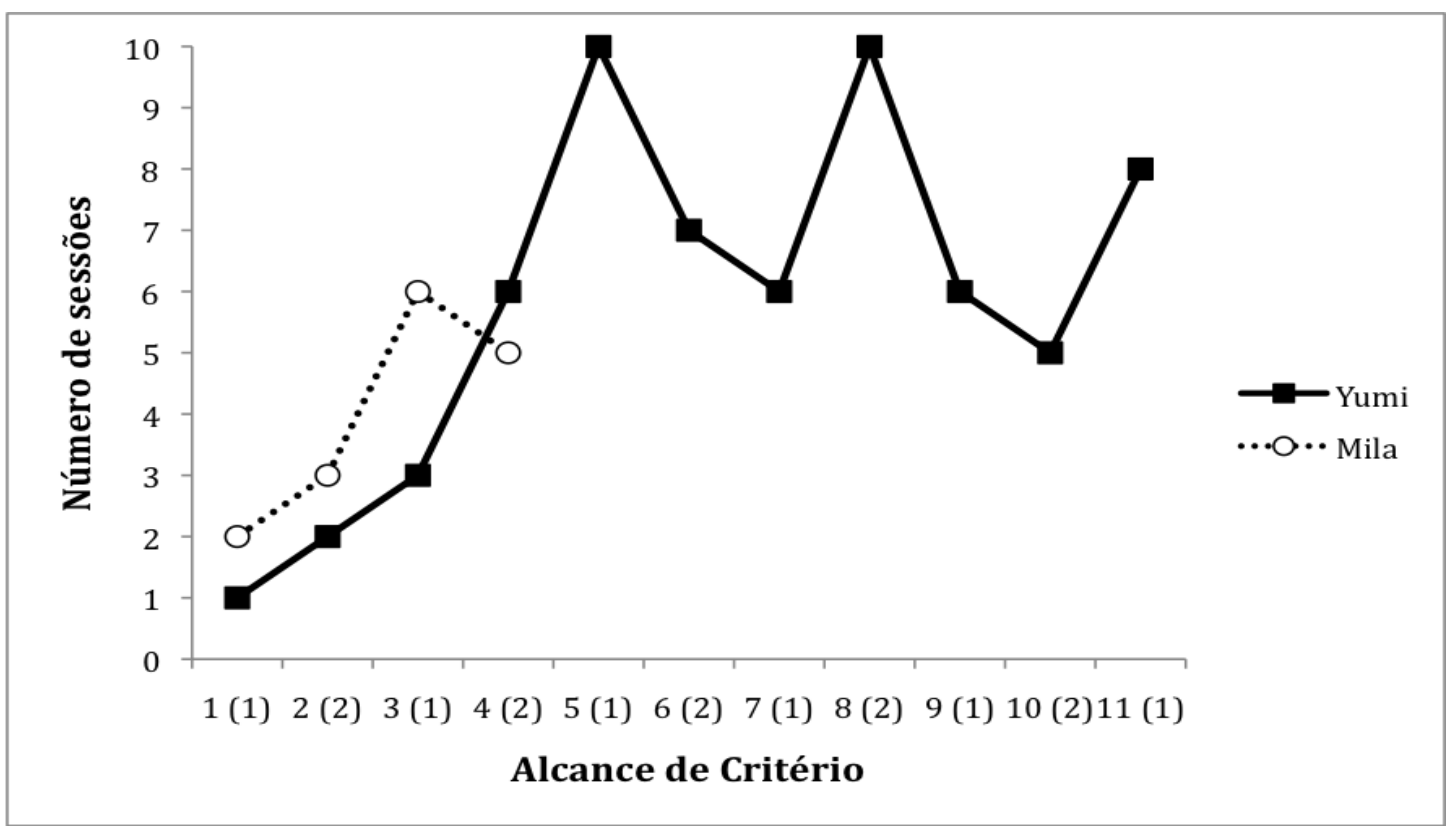

Figura 3. Número de sessões realizadas para cada alcance de critério (seis tentativas corretas consecutivas) para reversão de função com Yumi e Mila na Fase 3. Entre parênteses no eixo x, é apresentada a classe de estímulos utilizada como S+ [(1) para A1B1 e (2) para A2B2] em cada alcance. Por exemplo, para alcançar critério pela primeira vez (número 1 fora dos parênteses do eixo x), com o par de estímulos da classe 1 enquanto positivo [(1) no eixo x], Yumi realizou uma sessão e Mila, duas.

O experimento foi encerrado com Yumi após ela ser exposta a 70 sessões sem apresentar learning set da tarefa RRDSC na Fase 3 (com dois pares de estímulos olfativos por sessão), e com Mila na $16^{\mathrm{a}}$ sessão da Fase 3. Apesar de Mila não ter sido exposta às 70 sessões estabelecidas como critério para término da fase, verificou-se nas sessões realizadas que seu responder se assemelhava ao de Yumi na mesma fase, visto que não havia diminuição no número de sessões necessárias para alcance de critério.

\section{Retomada do treino inicial de RRDSC (Fase 1) com Lucke}

Como explicitado anteriormente, foi retomado o treino inicial de RRDSC com os estímulos 'café' e 'essência' com Lucke, tendo-se o cuidado de não colocar o recipiente com função negativa na posição na qual se encontrava na tentativa anterior o recipiente com função positiva. A Figura 4 mostra o número de sessões realizadas por Lucke para cada alcance de critério nessa fase. O critério para reversão de função foi alcançado seis vezes em um total de 39 sessões. 


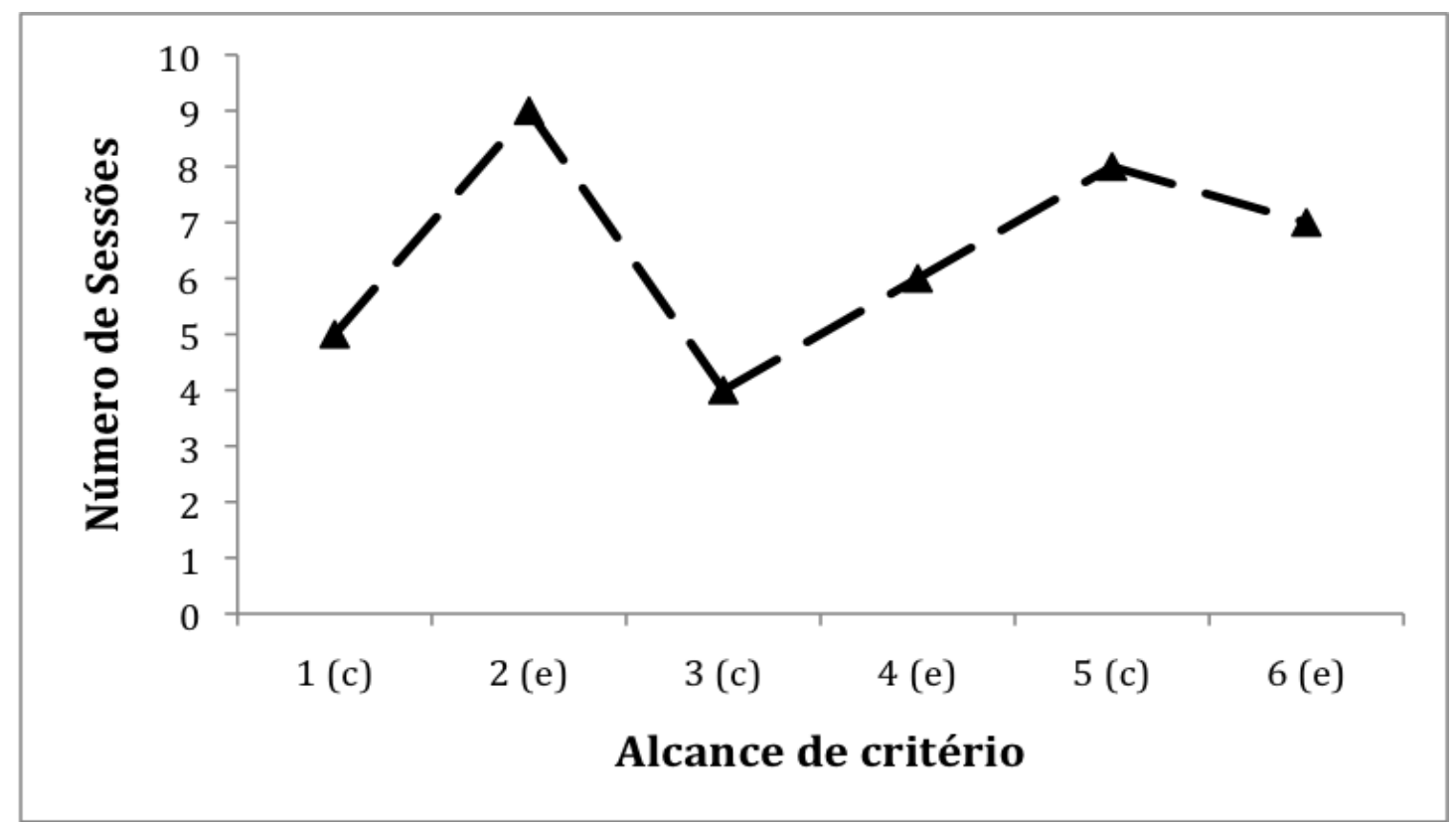

Figura 4. Número de sessões realizadas para cada alcance de critério para reversão de função com Lucke na retomada do treino inicial de RRDSC (retomada da Fase 1). Os alcances de critério realizados com a substância 'café' estão indicados pela letra "c" entre parênteses no eixo x (três alcances em 17 sessões), e os alcances de critério com a substância 'essência' estão indicados pela letra "e" entre parênteses no eixo x (três alcances em 22 sessões).

Portanto, Lucke foi exposto novamente à Fase 1 sem apresentar learning set da tarefa de RRDSC, indicando que ele necessitaria de muitas sessões para aprender a responder discriminadamente aos estímulos olfativos usados no experimento. Considerando isso, sua participação no estudo foi encerrada.

\section{DISCUSSÃO}

O procedimento do presente estudo se mostrou eficaz para ensinar o repertório de RRDSC com estímulos olfativos para dois cães domésticos. Destaca-se 1) o responder de Mila na Fase 1, que apresentou learning set da tarefa de RRDSC com os estímulos 'café' e 'essência', e 2) o desempenho de Mila e Yumi na Fase 2, ao alcançarem o critério de reversão de função para cada um dos quatro estímulos usados e mostrarem evidência de learning set: Yumi com relação ao treino da Fase 1 e ao necessitar apenas de uma sessão para o critério de cada par de estímulos na Fase 2, e Mila também com relação ao treino da Fase 1 e ao apresentar uma redução no número de sessões para o critério com o último par de estímulos na Fase 2.

A Fase 3 foi interrompida com Lucke logo após o alcance de critério com A1B1 em decorrência de sua dificuldade em responder de acordo com a contingên- cia em vigor. Enquanto Yumi e Mila alcançaram o primeiro critério de reversão de função em uma sessão, Lucke precisou realizar 18 sessões. Com a posterior análise de que ele estava respondendo sob controle da posição dos estímulos positivos (respondia repetidas vezes em recipientes com função S- quando eles se encontravam na mesma posição onde recipientes com função $\mathrm{S}+$ se encontravam na tentativa anterior), foi retomado o treino inicial de RRDSC com esse sujeito. Tal retorno à Fase 1 não produziu uma melhora no desempenho de Lucke, e por isso ele não foi exposto novamente à Fase 3.

$\mathrm{Na}$ Fase 3, Yumi apresentou um desempenho inicial semelhante ao observado nas fases anteriores, ou seja, poucas sessões eram necessárias até que o critério de reversão de função fosse atingido (foram necessárias uma, duas e três sessões para que fossem alcançados os critérios). No entanto, ela entrou no cio e passou vinte dias sem comparecer às sessões. Ao retornar para a coleta de dados, Yumi passou a realizar mais sessões para alcançar o critério (seis, 10 e sete sessões nos alcances 4, 5 e 6, por exemplo). Como Mila e Yumi alcançavam critério entre uma e 10 sessões na Fase 3, acredita-se que com a continuidade do treino elas poderiam aprender a responder adequadamente às classes de estímulo. No entanto, essa aprendizagem 
poderia demandar um número muito elevado de sessões (como no estudo de Vaughan, 1988, no qual foram necessárias mais de 800 sessões para ensinar pombos a responder a dois grupos de 20 estímulos), inviabilizando a continuidade dos sujeitos na pesquisa.

Apesar dos resultados desse estudo terem confirmado dados da literatura sobre a capacidade discriminativa olfativa de cães (Miklósi, 2007; Williams \& Johnston, 2002), eles não replicaram Domeniconi et al. (2008) no que concerne à obtenção de classes funcionais via o procedimento de RRDSC com cães domésticos. No presente estudo, não houve indicativos de formação de classes funcionais, visto que os sujeitos necessitavam de muitas sessões para alcançar critérios de reversão de função.

Acredita-se que tal dificuldade possa ter ocorrido em função da complexidade da tarefa. Os sujeitos tinham que responder discriminativamente a dois cheiros, e não responder a outros dois cheiros, sendo que os quatro eram apresentados simultaneamente em uma tentativa. É possível que a apresentação dos estímulos em pares facilitasse a discriminação, exigindo um número menor de sessões do que foi necessário no presente experimento para alcance de critério. Além disso, é possível que a proximidade dos estímulos dificultasse ainda mais a discriminação, pois os odores das substâncias poderiam se misturar.

A passagem da Fase 2 para a Fase 3 também pode ter sido muito abrupta, tendo em vista a apresentação de dois recipientes com função $\mathrm{S}+\mathrm{e}$ dois com função S- na mesma sessão após um treino com somente um recipiente de cada. A passagem por fases intermediárias, como a apresentação de dois recipientes com função $\mathrm{S}+$ e um com função $\mathrm{S}$-, ou o inverso, poderia consistir em um treino mais eficaz.

Dessa forma, sugere-se a realização de novos estudos, no intuito de treinar classes funcionais com estímulos olfativos em cães de maneira mais adequada e rápida. É possível que uma replicação parcial do procedimento de Lionello-DeNolf et al. (2008), no qual os estímulos foram apresentados em pares (um S+e outro S-) a cada tentativa, seja mais efetiva do que o procedimento descrito no presente trabalho.

\section{REFERÊNCIAS}

Barros, R.S., Souza, C. B. A., \& Costa, T. D. (2013). Funcitonal classe formation in the context of a foraging task in capuchin monkeys. Journal of the Experimental Analysis of Behavior, 100, 79-87.

Dahás, L. J. S., Brasiliense, I. C. S., Barros, R. S., Costa, T. D., \& Souza, C. B. A., (2010). Formação de classes funcionais em cães domésticos: uma abordagem da aquisição de comportamento pré-simbólico. Acta Comportamentalia, 18, 317-346.

Domeniconi, C., Bortoloti, R., Antoniazzi, L. C. K., \& Mendes, T. E. N. (2008). Treinos de discriminação simples e formação de classes funcionais de estímulos por cães. Interação em Psicologia, 12, 235-243.

Goldiamond, I. (1966). Perception, language, and conceptualization rules. In: B. Kleinmuntz (Org.), Problem solving (pp. 183-224). New York: Wiley.

Harlow, H. F. (1949). The formation of learning sets. Psychological Review, 56, 51-65.

Kaminski, J., Call, J., \& Fischer. J. (2004). Word learning in a domestic dog: Evidence for "fast mapping". Science, 304, 1682-1683.

Kastak, C. R., Schusterman, R. J., \& Kastak, D. (2001). Equivalence classifications by California see lions using class-specific reinforces. Journal of the Experimental Analysis of Behavior, 76, 131-158.

Lionello-DeNolf, K. M., McIlvane, W. J., Canovas, D. S., de Souza, D. G., \& Barros, R. S. (2008). Reversal learning set and functional equivalence in children with and without autism. The Psychological Record, 58, 15-36.

Miklósi, A. (2007). Dog: Behavior, evolution and cognition. New York: Oxford University Press.

Range, F., Aust, U., Steurer, M., \& Huber, L. (2008). Visual categorization of natural stimuli by domestic dogs. Animal Cognition, 11, 339-347.

Rico, V. V. (2006). Persistência comportamental e topografía de controle de estímulos coerente em treino de discriminação simples e escolha condicional por identidade ao modelo com quatro escolhas em macaco-prego (Cebus apella) (Dissertação de Mestrado). Universidade Federal do Pará, Belém - PA.

Rossi, A. (2008). Adestramento inteligente: Com amor, humor e bom senso. São Paulo: CMS Editora.

Sidman, M., \& Tailby, W. (1982). Conditional discrimination vs. matching to sample: An expansion of the testing paradigm. Journal of the Experimental Analysis of Behavior, 37, 5-22.

Sidman, M., Wynne, C. K., Maguire, R.W., \& Barnes, T. (1989). Functional classes and equivalence relations. Journal of the Experimental Analysis of Behavior, 52, 261-274. 
Slotnick, B., Hanford, L., \& Hodos, W. (2000). Can rats acquire an olfactory learning set. Journal of Experimental Psychology: Animal Behavior Processes, 26, 399-415.

Soproni, K., Miklósi, A., Csányi, V., \& Topál, J. (2001). Comprehension of human communicative signs in pet dogs (Canis familiaris). Journal of Comparative Psychology, 115, 112-126.

Udell, M., \& Wynne, C. (2008). A review of domestic dogs (Canis familiars) human-like behaviors: or why behavior analysts should stop worrying and love their dogs. Journal of the Experimental Analysis of Behavior, 89, 247261.

Vaughan, W. Jr. (1988). Formation of equivalence sets in pigeons. Journal of Experimental Psychology: Animal Behavior Processes, 14, 36-42.

Williams, M., \& Johnston, J. M. (2002). Training and maintaining the performance of dogs (Canis familiaris) on an increasing number of odor discriminations in a con- trolled setting. Applied Animal Behaviour Science. 78, 55-65.

Wobber, V. E. (2005). The evolution of cooperative signal comprehension in the domestic dog (Canis familiaris) (Doctoral dissertation). Harvard University, Cambridge, Massachusetts.

\section{Notas:}

* Este trabalho é parte da tese de doutorado da primeira autora orientada pelo último autor, desenvolvida no Programa de Pós-Graduação em Teoria e Pesquisa do Comportamento, da Universidade Federal do Pará. Ele foi financiado pelo CNPq no âmbito do Instituto Nacional de Ciência e Tecnologia Sobre Comportamento, Cognição e Ensino, e por meio de bolsa de doutorado para a primeira autora e produtividade em pesquisa para o último. Agradecemos a Anne Kelly Gonçalves pelo auxílio na coleta de dados.

1 O uso original do termo learning set se referia ao desempenho cada vez mais acurado de discriminação de diferentes estímulos (o mesmo uso de Slotnick et al., 2000). Já Lionello DeNolf et al. (2008) utilizaram o termo para se referir a um responder eficiente às contingências de reversão, maximizando reforços e minimizando erros, ao que denominam learning set de reversões. 